\title{
EL HUMOR GRÁFICO Y LA EDUCACIÓN DE LA MIRADA AMBIENTAL
}

\section{Comics and the education of an environmental gaze}

\author{
Veronica Carolina Hollman \\ Doctora en Ciencias Sociales. Investigadora del CONICET y \\ Profesora en la Universidad Nacional del Centro de la Provincia de Buenos Aires \\ vhollman@conicet.gov.ar
}

Artigo recebido em 12/07/2012 e aceito para publicação em 31/07/2012

RESUMEN: La producción y circulación de imágenes ha sido clave en la difusión de las ideas y agendas ambientales. Las imágenes han sido utilizadas como un documento irrefutable de los problemas ambientales y también, como un medio para generar emoción y activar un compromiso en las conductas individuales y colectivas. Las indagaciones que han examinado las representaciones visuales de la naturaleza han privilegiado géneros visuales como la fotografía, el cine y la pintura. En cambio, el humor gráfico - viñetas, comics, historietas- ha sido escasamente analizado. Partimos de la premisa que investigar la relación entre imágenes humorísticas y la cuestión ambiental nos ofrece interesantes elementos para entender el rol que desempeña la cultura visual en la construcción de sentidos y significaciones acerca de la de la naturaleza. Tomamos como corpus de análisis las imágenes humorísticas con contenido ambiental publicadas desde 1996 hasta el año 2010 en una revista de gran circulación en Argentina. Algunos de los interrogantes que articulan esta indagación son los siguientes: ¿Qué temas se introducen desde el humor gráfico como problemas ambientales? ¿Qué relaciones existen entre la agenda ambiental que se configura desde la revista y la que se delinea desde sus secciones de humor? Finalmente nos preguntamos cuáles son las particularidades/potencialidades que este género de imágenes ofrece para pensar la educación ambiental.

Palabras clave: cultura visual- naturaleza- humor gráfico-mirada ambiental

ABSTRACT: Images have played a key role in the communication of environmental ideas since the origins of environmental movements whether to prove environmental problems or to provoke personal and collective commitment. Researchers have mainly analyzed the visual representations of nature through pictures, photographs and films. Environmental issues that comics arise as well as their power to educate an environmental gaze have been hardly studied. We propose to analyze comics that put forward environmental issues in an Argentinean magazine (1996-2010) with the assumption that they can offer interesting elements to understand the relationship between visual culture and the social construction of nature. We ask which are the environmental topics introduced by comics and what sort of relations can be identified between the environmental agenda of the magazine and the environmental issues raised by the comics. Finally, we discuss what kind of power comics have to construct environmental education.

Keywords: visual culture- nature- comics- environmental gaze 


\section{INTRODUCCIÓN}

In a world which is expanding day by day, literature is no longer enough... Our busy age does not always have time to read, but it always has time to look.Théolipe Gautier, 1858 (citado en Schwartz, 1996:16)

La producción y circulación de imágenes ha sido clave en la difusión de las ideas y agendas desde los orígenes de los movimientos ambientales. En efecto, la historia de estos movimientos sociales indica que algunas de las imágenes seleccionadas para sus campañas se convirtieron en verdaderos íconos de lemas ambientales. Blue Marble, una de las fotografías de la Tierra capturada en los viajes realizados a la Luna entre 1968 y 1972, es, sin duda, una imagen emblemática que todavía se emplea en diversas campañas ambientales. Pero también podríamos mencionar otras imágenes como la caricatura del oso panda, ícono de una organización ambiental y de una idea -la existencia de especies animales en riesgo de extinción- o la fotografía del barco de Greenpeace, emblema de las luchas de esta organización ambiental. La apelación a las imágenes para comunicar la cuestión ambiental no es fortuita: como queda explicitado en el epígrafe, nuestra cultura se orienta cada vez más y con mayor fuerza a la creación y comunicación de significados a través de los medios visuales (MIRZOEFF, 2003; ROGOFF, 2000).

Si bien los géneros de imágenes a los cuales se apela desde los movimientos ambientales son diversos, las fotografías han sido utilizadas con mayor frecuencia para hacer visibles los problemas ambientales a audiencias amplias y no especializadas en la temática. Es posible advertir que, en los medios periodísticos, las campañas publicitarias de organizaciones ambientales y los libros escolares, las fotografías toman dos funciones. Una función consiste en documentar los problemas ambientales; la otra, apela a emocionar y generar un impacto subjetivo, clave para activar un compromiso en las conductas individuales y colectivas.

Los trabajos que han estudiado la producción de las representaciones visuales de la naturaleza han analizado diferentes géneros de imágenes como pinturas (WOLFE, 2009; BAKER, 2009), fotografías (COSGROVE, 1994; DELUCA, 1999; POOLE,
2008; WELLING, 2009; GORMAN, 2009), películas (INGRAM, 2000; BRERETON, 2005; MURRAY \& HEUMANN, 2009; WILLOQUET-MARICONDI, 2010). Las investigaciones ya realizadas sugieren que es necesario analizar cómo utilizamos las imágenes para construir y reforzar una suerte de memoria ambiental. Resta explorar aún, las particularidades de las imágenes humorísticas - viñetas, comics, historietas- para exponer una agenda ambiental así como sus potencialidades en pos de una educación ambiental.

Partimos de la premisa que investigar la relación entre imágenes humorísticas y la cuestión ambiental nos ofrece interesantes elementos para entender el rol que desempeña la cultura visual en la construcción de sentidos y significaciones acerca de la naturaleza y su transformación. En primer lugar, debemos señalar que estas imágenes tienen una mayor circulación en función de su publicación en diarios y revistas. Por consiguiente, nos ofrecen la posibilidad de aproximarnos a la identificación de una red de sentidos que se construye más allá de la educación formal. Discutiremos que las imágenes humorísticas exponen elementos que forman parte de una memoria ambiental y que resultan fácilmente reconocibles para todos los integrantes de una sociedad -pues también circulan en otros discursos visuales como las publicidades, las disciplinas escolares, los documentales, los murales-. En segundo lugar, las características propias de este género de imágenes nos invitan a imaginar hendijas para que la educación ambiental, tradicionalmente más centrada en una perspectiva biológica (PELEGRINI y VLACH, 2011), tenga un anclaje en su contenido político, económico y cultural.

En este artículo proponemos analizar las imágenes humorísticas publicadas en la Revista Viva, una revista de lectura fácil y amena que acompaña la edición del día domingo del diario Clarín, entre los años 1996 y 2010. Algunos de los interrogantes que articulan esta indagación son los siguientes: ¿Qué temas se introducen desde el humor gráfico como problemas ambientales? ¿Qué relaciones existen entre la agenda ambiental que se configura desde la revista y la que se delinea desde sus secciones de humor? Finalmente, nos preguntaremos cuáles son las particularidades/ potencialidades que ofrece este género de imágenes para pensar la educación ambiental.

Soc. \& Nat., Uberlândia, ano 24 n. 2, 227-242, mai/ago. 2012 


\section{EL HUMOR GRÁFICO EN LA REVISTA VIVA}

La revista Viva se destaca en el universo de revistas argentinas en función de la cantidad de ejemplares en circulación (Ver Tabla 1). Sus lectores son catalogados en el mundo del marketing como multitarget: la revista constituye un valioso espacio para la promoción de productos de amplio espectro. $\mathrm{Su}$ registro temático, el diseño y la edición de los textos periodísticos se articulan para promover una lectura fácil y amena. Es una revista para "ver, pensar y sentir", según se enuncia desde la editorial, característica que se evidencia en un conjunto de secciones de amplio espectro: entretenimiento - humor gráfico, juegos de ingenio-, actualidad - cultura, tecnología, salud, ambiente, viajes- y otras aún más variadas como el horóscopo semanal, recetas de cocina, moda y belleza. A pesar de que el diario Clarín tiene sus contenidos disponibles en Internet, la revista sigue manteniendo su formato en papel y su contenido no está disponible on-line. Esta exclusividad en la accesibilidad a través del formato papel y su diseño refuerzan una suerte de recorrido visual como modalidad de lectura de la revista. No resulta un dato menor decir que es frecuente encontrar esta revista en ámbitos donde se realiza una lectura casual con una extensión temporal variable como en salas de espera de consultorios y en las mesas de los bares.

Tabla 1: Circulación neta pagada de revistas semanales. Promedios por edición del mes de Mayo 2012 expresados en ejemplares.

\begin{tabular}{|l|c|}
\hline REVISTA & \\
\hline Viva & 598899 \\
\hline La Nación Revista & 359418 \\
\hline Pronto Semanal & 105844 \\
\hline Paparazzi & 98499 \\
\hline Billiken & 67995 \\
\hline Genios & 71944 \\
\hline Caras & 57258 \\
\hline N Revista de Cultura Clarín & 37024 \\
\hline El Gráfico & 24550 \\
\hline National Geographic & 18691 \\
\hline
\end{tabular}

Elaboración propia. Fuente: Estadísticas del Instituto Verificador de Circulaciones.

Disponibles en: http://www.ivc.org.ar/consulta

El diseño asume un rol clave en la búsqueda constante de la combinación de informar y entretener. El tema central - nota con mayor extensión de páginas- se expone en la tapa con una imagen que ocupa prácticamente toda la hoja de apertura y un título que orienta al lector; también algunas de las notas complementarias se presentan en los márgenes superior o inferior.

Ya desde los inicios de la publicación, el diseño se orientó al desarrollo de un gran despliegue visual con claro predominio del género fotográfico dentro de un variado repertorio de imágenes. Algunas de las características más sobresalientes del diseño son: la alta proporción de imágenes en relación al número de hojas, el tamaño asignado a ellas -media página, página completa o doble página- $\mathrm{y}$ la presencia indiscutible del color -asegurado por la calidad de la impresión-. En resumen, la diversidad temática y las estrategias de diseño invitan a los lectores a recorrer la revista y detener sus ojos en sus distintas secciones. En este contexto visual, las imágenes, desde su color y tamaño, captan la atención de los ojos y si consiguen el interés del lector, lo invitan a seguir con la lectura del artículo.

El humor gráfico es uno de los géneros de imágenes que ha tenido un lugar propio en la revista. Recordemos que si bien en Argentina la publicación de revistas satíricas se remonta a la segunda mitad del siglo XIX, a partir de la década de 1990 la desaparición de las publicaciones de humor gráfico tuvo como contrapunto la afirmación de los diarios (y sus revistas) como espacios de circulación de la producción de los principales humoristas argentinos: Rep, Rudy, Daniel Paz, Liniers en el diario Página/12; Fontanarrosa, 
Tabaré, Crist, Sendra, Sábat, Landrú, Quino, Altuna y Trillo, Caloi, Dobal, Cardo en el diario Clarín; Huadi, Liniers, Maitena, Nik, Heredia, Mordillo, Nine en el diario La Nación (BURKART, 2009).

Tres reconocidos humoristas argentinos han sido, en la mayor parte del período bajo análisis, los autores del humor gráfico de la revista Viva: Caloi, Quino y Fontanarrosa. Si bien estos humoristas han compartido el espacio de publicación de sus trabajos, cada uno de ellos ha delineado un estilo propio e irrepetible en la estética visual, la combinación de elementos del género y las temáticas abordadas. El estilo personal de los humoristas se plasma en alguna referencia directa al nombre de su creador como título para cada sección de humor.

En los diarios, el humor gráfico tiene la función de ilustrar la noticia o la editorial del día. Como consecuencia su contenido está directamente marcado por la agenda diaria de noticias. En la revista Viva, en cambio, las imágenes humorísticas tienen vida propia: cuentan con un espacio específico -a cada viñeta o tira se le asigna una página entera-, no ilustran una noticia y gozan autonomía temática respecto de la agenda general de la publicación. Hemos encontrado la reutilización de algunas imágenes humorísticas. Si bien esta repetición puede obedecer a diversos motivos (tales como la optimización de recursos editoriales, la escasez de otras opciones, la menor producción de los humoristas o la culminación de su relación contractual con la revista), nos orientamos a sugerir que en la amplitud temática y temporal de un humor gráfico creado sin la imposición de la actualidad de las noticias podría encontrarse la razón principal.

El humor gráfico en la revista Viva toma básicamente dos modalidades: la viñeta y la tira. La viñeta, una ilustración acompañada o no por un texto breve, es la modalidad gráfica más utilizada en el período analizado. La tira, una serie de viñetas unidas por un argumento, se utiliza en menor proporción. Los tres humoristas emplean, como examinaremos más adelante, los diversos elementos del humor gráfico recopilados por Kleeman (2006): el simbolismo, las metáforas visuales, los estereotipos, las caricaturas, la exageración y la distorsión, los subtítulos o leyenda.

\section{LAAGENDAAMBIENTAL DESDE EL HUMOR GRÁFICO}

La sección de humor gráfico, en todo el período analizado, no es ajena a la introducción y categorización de la cuestión ambiental como uno de los problemas del mundo contemporáneo. Es decir, los temas ambientales ingresan en una sección de la revista cuya finalidad explícita es el entretenimiento y de este modo, se invita a ponerlas en relación con la ironía, la sátira y la parodia. Con sutileza, desde el humor gráfico se comienza mostrar la inaceptabilidad de determinados niveles de transformación de la naturaleza. En esta sección identificamos los temas que se presentan como problemas ambientales desde las imágenes humorísticas y los pondremos en diálogo con el temario ambiental de la revista.

Podríamos reconstruir la agenda ambiental expuesta desde las imágenes humorísticas en tres categorías: i- problemas ambientales, ii- crítica a nuestra modalidad de relación con la naturaleza, iii- crítica a nuestra percepción sobre la naturaleza y sus niveles de transformación (Ver Tabla 2).

Soc. \& Nat., Uberlândia, ano 24 n. 2, 227-242, mai/ago. 2012 
Tabla 2: La agenda ambiental desde el humor gráfico de la revista Viva

\begin{tabular}{|c|c|c|c|}
\hline Categorías & Temáticas & $\begin{array}{c}\text { Año de } \\
\text { publicación }\end{array}$ & Formato \\
\hline \multirow{6}{*}{ Problemas ambientales } & El "agujero" de Ozono & 1998 & Viñeta \\
\hline & $\begin{array}{l}\text { Los problemas ambientales en las } \\
\text { ciudades }\end{array}$ & $\begin{array}{l}1999 \\
2000 \\
2001\end{array}$ & $\begin{array}{l}\text { Viñeta } \\
\text { Viñeta } \\
\text { Tira }\end{array}$ \\
\hline & Contaminación industrial & $\begin{array}{l}1994 \\
2001 \\
2007 \\
\end{array}$ & $\begin{array}{l}\text { Viñeta } \\
\text { Viñeta } \\
\text { Viñeta } \\
\end{array}$ \\
\hline & La expansión de la producción de soja & 2001 & Tira \\
\hline & Contaminación del río Uruguay & $\begin{array}{l}2005 \\
2006 \\
2006\end{array}$ & $\begin{array}{l}\text { Viñeta } \\
\text { Viñeta } \\
\text { Viñeta }\end{array}$ \\
\hline & $\begin{array}{l}\text { Deforestación y su relación con el } \\
\text { cambio climático }\end{array}$ & 2007 & Viñeta \\
\hline \multirow{5}{*}{$\begin{array}{l}\text { Crítica a nuestra } \\
\text { modalidad de relación } \\
\text { con la naturaleza }\end{array}$} & La apropiación de la naturaleza & $\begin{array}{l}1999 \\
2004 \\
2010\end{array}$ & $\begin{array}{l}\text { Viñeta } \\
\text { Viñeta } \\
\text { Viñeta }\end{array}$ \\
\hline & (Des) conocimiento de la naturaleza & $\begin{array}{l}1994 \\
1995 \\
1996 \\
2000 \\
2001 \\
2005 \\
2005 \\
\end{array}$ & $\begin{array}{c}\text { Viñeta } \\
\text { Tira } \\
\text { Viñeta } \\
\text { Tira } \\
\text { Tira } \\
\text { Tira } \\
\text { Viñeta }\end{array}$ \\
\hline & La destrucción del planeta & $\begin{array}{l}1994 \\
1998 \\
1999 \\
2005 \\
2005 \\
2006 \\
2008\end{array}$ & $\begin{array}{c}\text { Tira } \\
\text { Tira } \\
\text { Tira } \\
\text { Viñeta } \\
\text { Tira } \\
\text { Viñeta } \\
\text { Viñeta }\end{array}$ \\
\hline & $\mathrm{La}$ artificialización de la naturaleza & $\begin{array}{l}1994 \\
1994 \\
1995 \\
1995 \\
2007 \\
\end{array}$ & $\begin{array}{c}\text { Viñeta } \\
\text { Viñeta } \\
\text { Viñeta } \\
\text { Tira } \\
\text { Viñeta } \\
\end{array}$ \\
\hline & 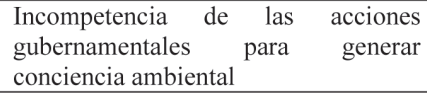 & $\begin{array}{l}2005 \\
2005 \\
2005\end{array}$ & $\begin{array}{l}\text { Viñeta } \\
\text { Viñeta } \\
\text { Viñeta }\end{array}$ \\
\hline \multirow[t]{2}{*}{\begin{tabular}{llr} 
Crítica a & \multicolumn{2}{r}{ nuestra } \\
percepción & de & la \\
naturaleza & y & su \\
transformación & &
\end{tabular}} & $\begin{array}{l}\text { La naturalización de los problemas } \\
\text { ambientales }\end{array}$ & $\begin{array}{l}1994 \\
2001 \\
2005 \\
2006 \\
2006 \\
2007 \\
2009 \\
2010 \\
\end{array}$ & $\begin{array}{c}\text { Tira } \\
\text { Tira } \\
\text { Viñeta } \\
\text { Tira } \\
\text { Viñeta } \\
\text { Viñeta } \\
\text { Viñeta } \\
\text { Viñeta } \\
\end{array}$ \\
\hline & $\begin{array}{l}\text { Cambios en la percepción de lo que se } \\
\text { considera natural }\end{array}$ & $\begin{array}{l}2009 \\
2010\end{array}$ & $\begin{array}{l}\text { Viñeta } \\
\text { Viñeta }\end{array}$ \\
\hline
\end{tabular}

Elaboración propia en base a relevamiento de Revistas Viva 1994-2010.

La categoría "problemas ambientales" comprende una serie de preocupaciones sobre la transformación de la naturaleza a escala global, regional y local. A partir del año 2005, detectamos un movimiento desde una problematización general de la degradación de la naturaleza (siempre causada por la sociedad) a una problematización que los sitúa en lugares concretos y con nombres propios. Así por ejemplo, de la exposición de la contaminación industrial comoun problemaen símismo, lasimágenes humorísticas pasan a mostrar las consecuencias de la contaminación producidas a partir de la instalación de una industria de papel celulosa en el río Uruguay (Figura 1). 
Figura 1: La identificación de problemas ambientales en lugares concretos

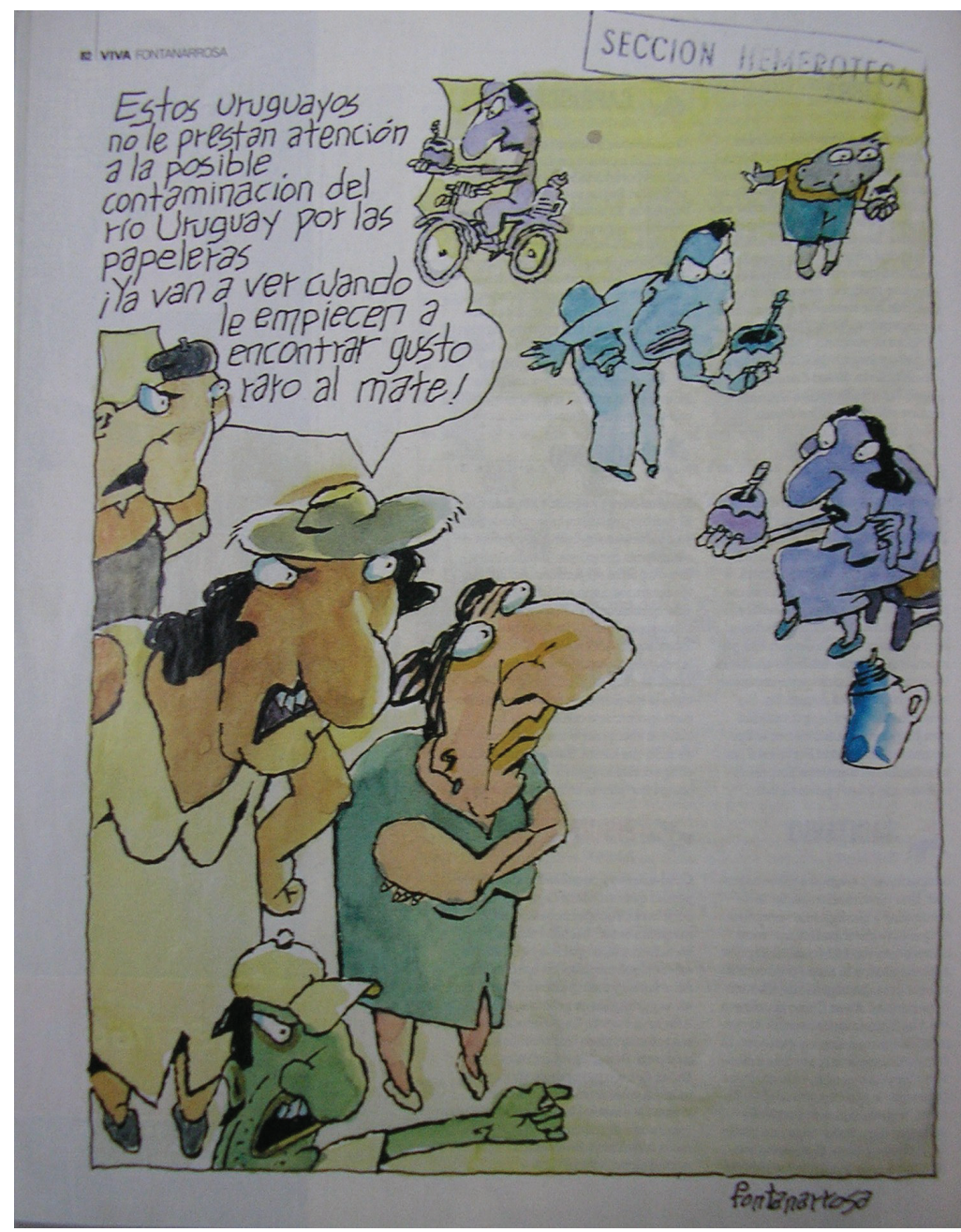

Fuente: Viva, 26 de Febrero 2006. Autor: Fontanarrosa.

Gentileza Hemeroteca de la Biblioteca Nacional.

La segunda categoría agrupa una serie de imágenes humorísticas que realizan una mirada crítica a nuestros modos de relacionarnos con la naturaleza. Se incluyen aquí temas tales como nuestro desconocimiento de los ciclos y procesos de la naturaleza, la preocupación excesiva por "recrear" determinados paisajes naturales (que en muchos casos trae consigo la destrucción de otros elementos naturales) hasta la incompetencia de las acciones gubernamentales para promover una conciencia ambiental. Por un lado, este grupo de imágenes expone visualmente el contenido histórico de la idea de naturaleza: cada sociedad en cada momento histórico construye una significación y otorga un valor/significación a la naturaleza (Figura 2). Por otro lado, el humor expresa visualmente una idea muy presente en el sentido común: la naturaleza estática y en un equilibro perfecto siempre y cuando las sociedades puedan evitar romperlo (CRONON, 1996). 
Figura 2: Percepción de la naturaleza y su valoración social.

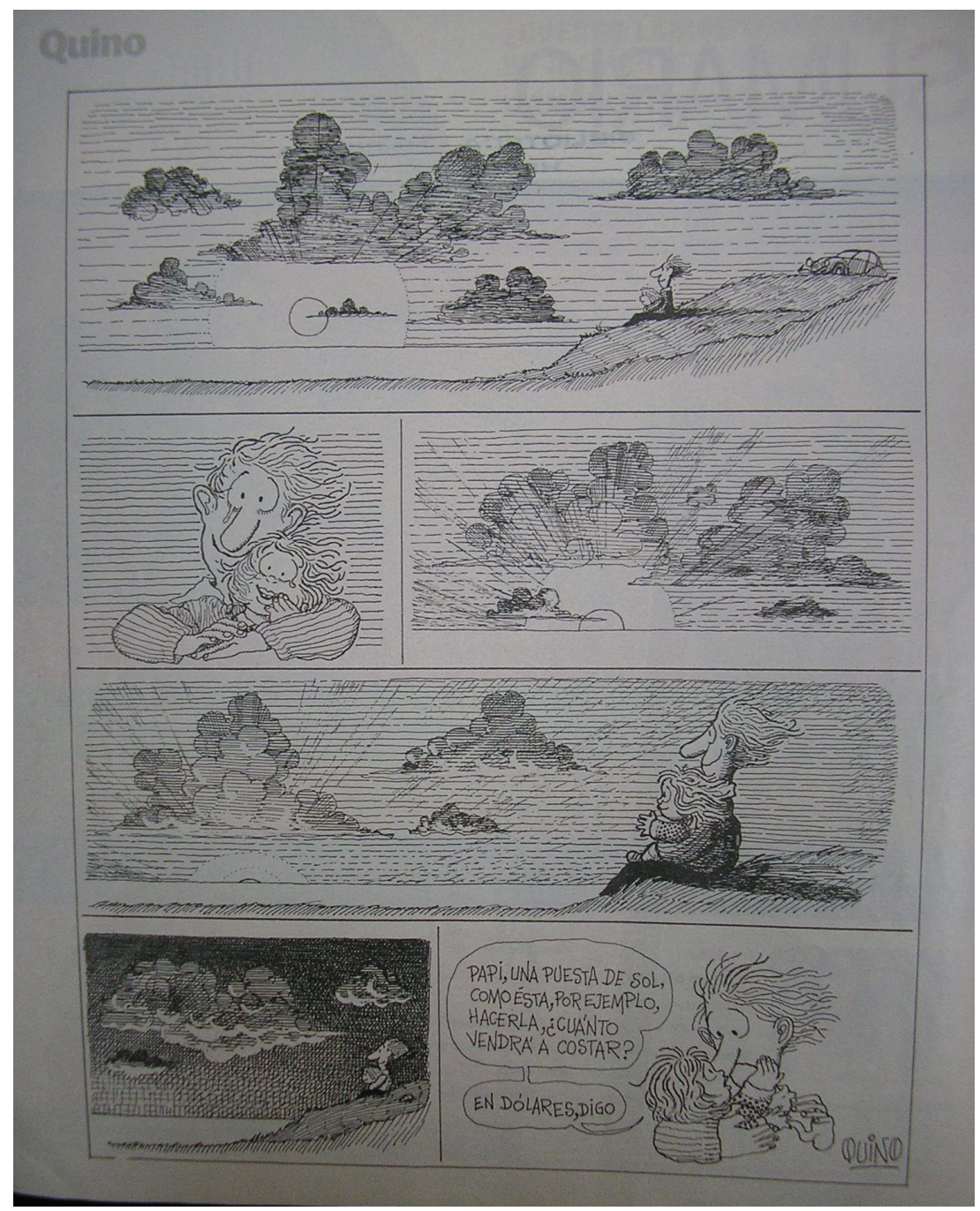

Fuente: Revista Viva, 31 de Agosto 2003.

Autor: Quino. Gentileza Hemeroteca de la Biblioteca Nacional.

La tercera categoría comprende imágenes que exponen diferentes percepciones sobre la aceptabilidad (o inaceptabilidad) de los niveles de transformación de la naturaleza. Tal vez, la potencia de estas imágenes reside en el despliegue de la idea que la degradación de algunos elementos de la naturaleza o su extinción no necesariamente constituye un problema ambiental para todas las sociedades (Figura 3).

$\mathrm{Si}$ establecemos un contrapunto entre la agenda ambiental de la revista y la de las páginas de humor, es posible detectar tres funciones asignadas a este género de imágenes:

i- Anticipa al tratamiento de las mismas temáticas en secciones de información a la agenda de la revista. Esto sucede con los siguientes problemas ambientales: la contaminación del río Uruguay y el adelgazamiento de la capa de ozono.

ii- Retoma temas ya tratados en la agenda general de la revista y los vuelve a colocar bajo discusión desde otras perspectivas. Este es el caso de los problemas ambientales que se viven en las grandes ciudades. 
iii- Expone problemas ambientales que en la agenda general de la revista no han tomado esta categoría. Uno de los ejemplos más notorios de esta modalidad es el caso de la creciente expansión del monocultivo de soja en Argentina: mientras que en todo el periodo analizado ningún artículo aborda esta problemática, ya en el año 2001, una tira de Fontanarrosa, presenta este cambio en el modelo productivo como un problema ambiental.

Figura 3: El carácter cultural e histórico de nuestra percepción y aceptación de los niveles de transformación de la naturaleza.

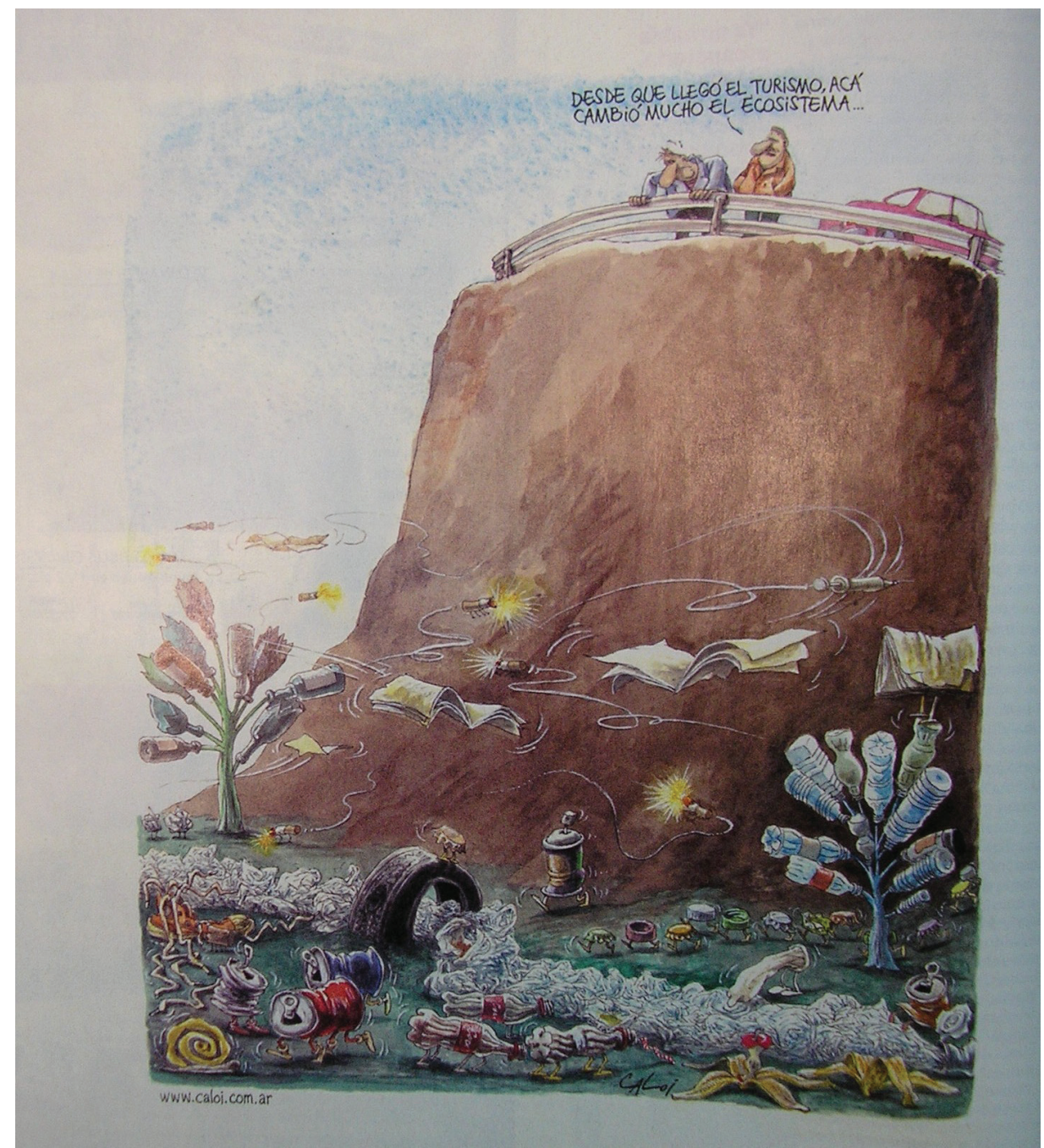

Fuente: Revista Viva, 6 de Agosto 2006. Autor: Caloi.

Gentileza Hemeroteca de la Biblioteca Nacional.

\section{CLAVES VISUALES DEL HUMOR GRÁFICO PARA EXPONER LA CUESTIÓN AMBIENTAL}

El sentido del humor hace descubrir muchas cosas en el mundo que sin él no se descubrirían. La risa no sólo es una cuestión diver- tida sino un modo de conocer la realidad. Antonio Cayo Moya (citado en El valor terapéutico del humor.

Desclée De Brouwer)

Soc. \& Nat., Uberlândia, ano 24 n. 2, 227-242, mai/ago. 2012 
Una de las potencialidades que se atribuye a las imágenes humorísticas es su habilidad y sencillez para comunicar ideas. Podríamos preguntarnos cuáles son las claves que hacen más accesible un mensaje a través de este género de imágenes, particularmente en la comunicación de temas ambientales. En esta sección identificaremos las claves visuales desplegadas en las imágenes humorísticas para comunicar ideas sobre el carácter problemático de la transformación de la naturaleza.

La metáfora visual se exhibe con recurrencia en las imágenes humorísticas analizadas. Se trata de un dibujo que evoca y sugiere, sin que sea una representación transparente del objeto o situación en cuestión, pues contiene elementos reconocibles para quien los mira. Recorramos algunas de las metáforas visuales del conjunto de imágenes analizadas a través de las imágenes seleccionadas en este trabajo: los uruguayos pintados de color azul insinúan algo extraño en el aspecto de las personas (Figura 2), la puesta de sol evoca la belleza de la naturaleza (Figura 3), los carteles con un porcentaje expuestos en la vidriera de un comercio de alimentos sugieren una promoción o rebaja (Figura 4). Estos ejemplos evidencian que la metáfora visual funciona cuando se conecta con usos, costumbres y experiencias que resultan habituales en un momento histórico y en un lugar determinado.

La ironía, la sátira y la parodia se encarnan en estas metáforas visuales y ponen en ridículo supuestos sobre la naturaleza, la posible incidencia en nuestras vidas de la contaminación del agua y del aire, el interés en la ecología por parte de algunos actores sociales (como los empresarios) y la efectividad de las acciones gubernamentales.

Figura 4. Claves visuales para exponer la cuestión ambiental

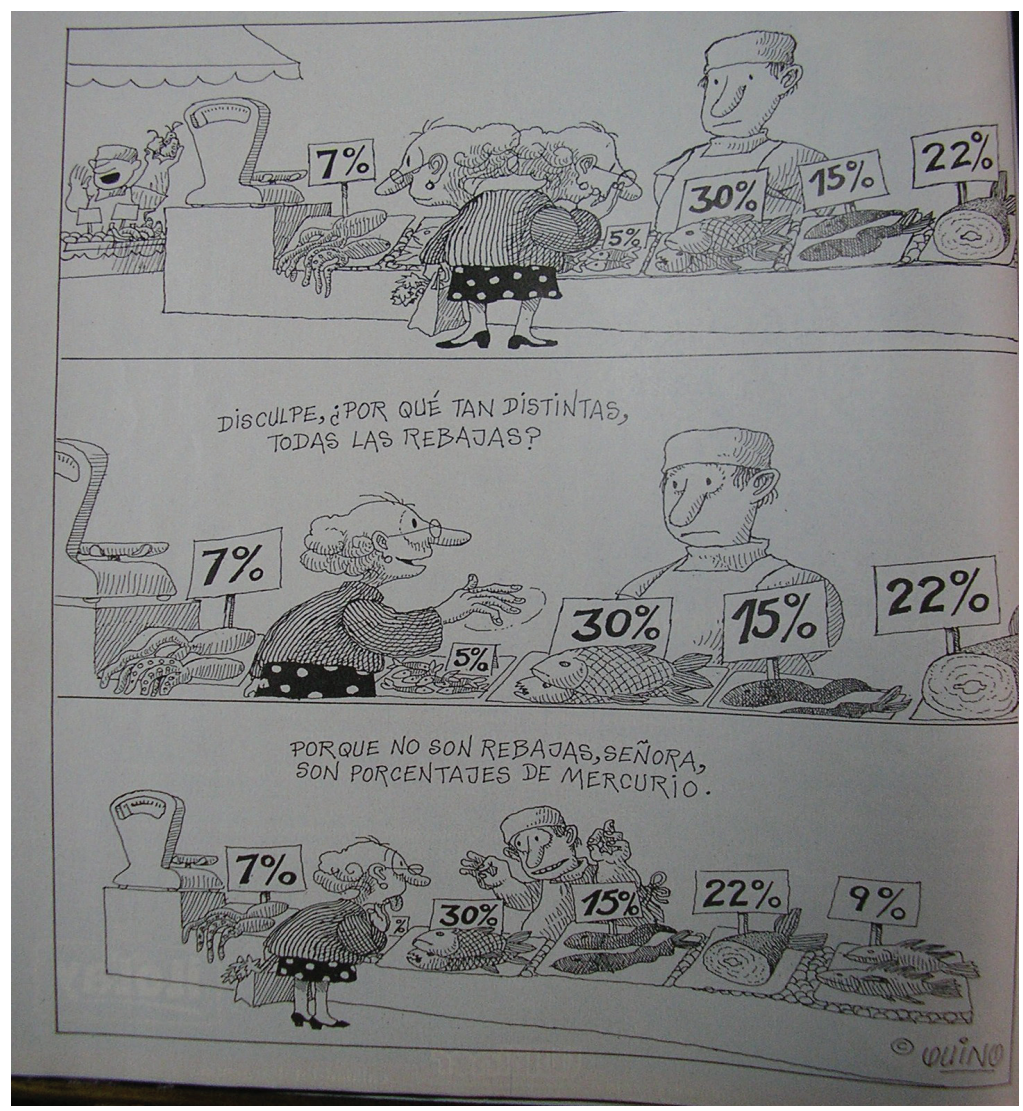

Fuente: Revista Viva, 26 de Noviembre 2006.

Autor: Quino. Gentileza Hemeroteca de la Biblioteca Nacional. 
La leyenda o subtítulo, otro de los elementos del humor gráfico, actúa solidariamente con la metáfora visual: ofrece un contrapunto de lo que se muestra y contextualiza los contenidos visuales de la imagen. También se emplea para que la audiencia pueda referenciar el problema, localizarlo en un lugar concreto o identificar los actores sociales involucrados. Si volvemos a mirar la Figura 4, podemos advertir la función de contextualización del subtítulo y lo que nos sugiere: los carteles ya no son los porcentajes de descuentos sino que toman una nueva significación al leer que hacen referencia al nivel de mercurio contenido en los alimentos.

Las leyendas presentan como normal aquello que nos puede resultar extraño, imposible o inadmisible. A través de este elemento visual se busca interpelar la mirada y provocar un conflicto en la frontera de lo normal/anormal. Así por ejemplo, los subtítulos de la Figura 3 señalan la aceptabilidad de los desechos provocados por la actividad turística y su integración al paisaje -una especie más dentro de los sistemas naturales-. El mensaje se convierte en un llamado de atención para las audiencias porque todavía nos resulta extraño visitar en plan turístico un paisaje con la función de basural.

Las caricaturas - expresiones de los rostros, animales que se expresan verbalmente, personajes míticos como Adán y Eva, del planeta Tierra- generan empatía, identificación o rechazo por parte de las audiencias. También, éstas indican el registro ficcional de la imagen. Es decir, caricaturar implica reconocer que no se representa objetivamente un problema ambiental sino que se muestra una perspectiva de éstos. El registro ficcional, asimismo, supone aceptar que las consecuencias aludidas no son el único final posible de la historia.

Figura 5: La exageración visual en combinación con la leyenda.

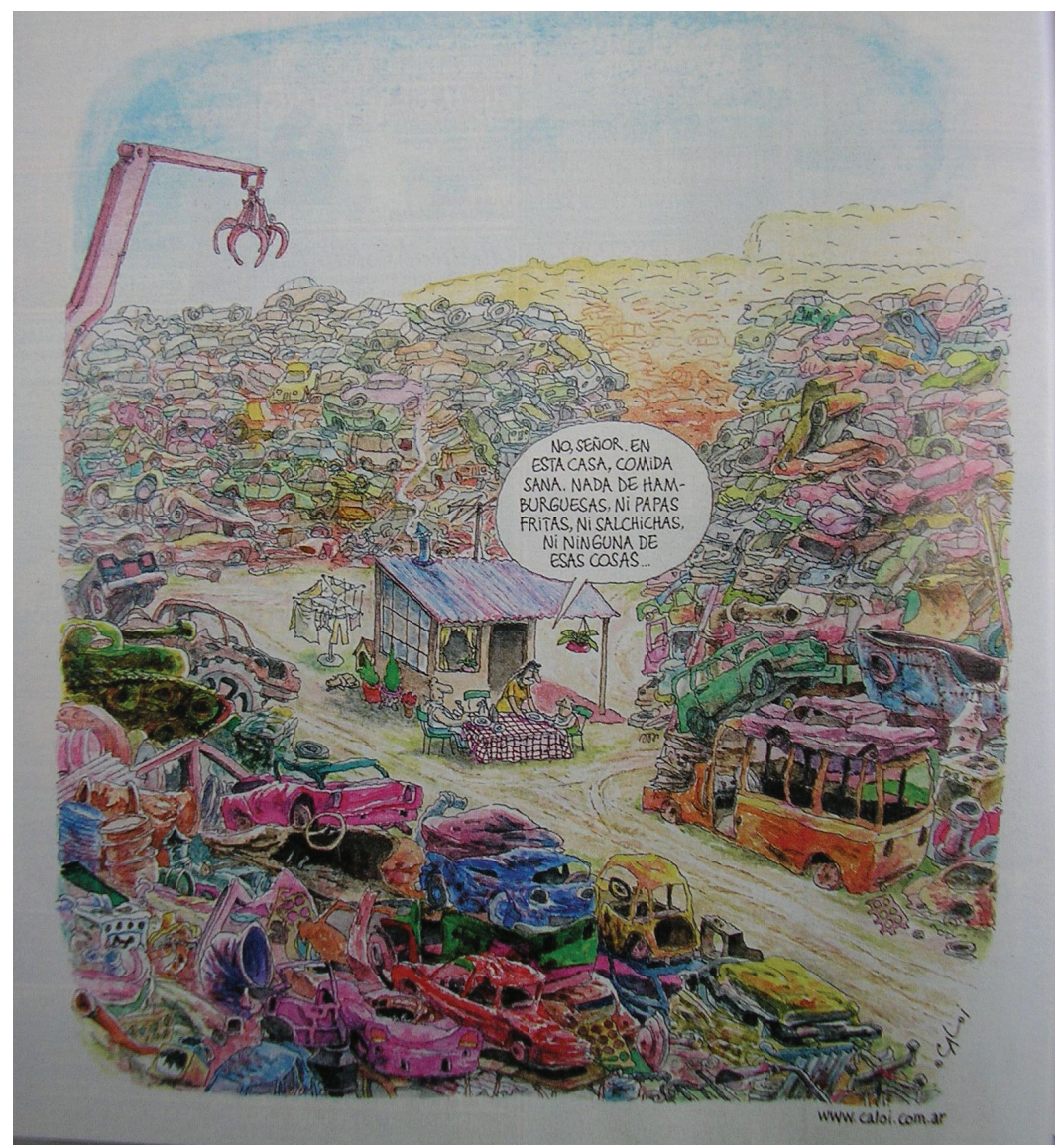

Fuente: Revista Viva, 8 de Junio 2008.

Autor: Caloi. Gentileza Hemeroteca de la Biblioteca Nacional.

Soc. \& Nat., Uberlândia, ano 24 n. 2, 227-242, mai/ago. 2012 
La exageración o miniaturización, en combinación con símbolos y leyendas, constituyen otras de las claves visuales a las cuales se acude para exponer lo contrario de lo que se dice o bien, ridiculizar una posición con respecto a las consecuencias de la alteración de la naturaleza. La contaminación de un curso de agua producida por la instalación de una industria de papel celulosa se miniaturiza con un conjunto de barquitos de papel recorriendo el río. En cambio, la expansión del medio técnico en una ciudad se exagera al dibujar un grupo de personas disfrutando de un día recreativo en un espacio verde ficcional (un bosque pintado como telón de fondo) en el medio de un entramado interminable de autopistas. La exageración o miniaturización visual se convierten en imitaciones burlescas que sacuden nuestra mirada como en la Figura 5: vivimos en sociedades que cada vez producen más basura y simultáneamente, creemos que al adherir a un slogan de vida más saludable estamos modificando nuestro modelo de consumo.

\section{EN CLAVE HUMORÍSTICA: ALGUNOS ELE- MENTOS DE LA "MEMORIA AMBIENTAL"}

Las imágenes humorísticas exponen elementos que resultan reconocibles para todos los integrantes de una sociedad, en un momento histórico determinado, ya que también están presentes en otros discursos visuales como las publicidades, las disciplinas escolares, los documentales, los murales. Es decir, cada uno de los elementos visuales específicos de las imágenes humorísticas se vuelven efectivos siempre que nos permitan establecer conexiones con informaciones, conocimientos y experiencias construidas en el transcurso de nuestra vida y en función de nuestra pertenencia a una sociedad determinada. Identificaremos algunos de los elementos visuales que despliegan ideas presentes (y poco discutidas) sobre la naturaleza y su transformación social.

El humor gráfico retoma la idea de la naturaleza como espectáculo visual ante el cual nuestros ojos necesariamente se detendrán y se deslumbrarán. Una serie de estrategias visuales se ponen en juego en las viñetas y en las tiras para que los lectores reconozcan la belleza y unicidad de la naturaleza. Entre ellas destacaremos las siguientes:
- la inclusión de elementos pictóricos de paisajes "íconos" que en nuestra memoria visual geográfica ya los ordena como paisajes bellos y únicos, por ende, dignos de preservación. La selva amazónica, por ejemplo, es uno de estos paisajes.

- la recreación de escenas que recuperan nuestras experiencias sensoriales más primarias en relación a la observación de la naturaleza y nuestra relación con ella. Algunas de las escenas recurrentes son la observación de un atardecer o de una noche estrellada.

- la representación de naturaleza como algo externo siempre disponible para que nuestros ojos se detengan a apreciarla, activando así un conjunto de experiencias visuales ya construidas en torno a la visualización de pinturas y fotografías de naturaleza y paisajes.

Las consecuencias negativas de la transformación de la naturaleza se presentan a través de elementos de uso reiterado en el género fotográfico para retratar problemas ambientales: el humo que sale de las chimeneas de las fábricas, un color oscuro en el agua (aunque la contaminación del agua no afecte necesariamente su color), la acumulación de basura, un hombre y un rifle ante un animal o la ocurrencia de fenómenos meteorológicos de una fuerza inusitada. "Recordar es, cada vez más, no tanto recordar una historia sino ser capaz de evocar una imagen" (SONTAG; 2003:104). Es decir, las imágenes humorísticas recuperan determinados elementos visuales que nuestra memoria reconoce al evocar fotografías que hemos visto (y continuamos viendo) en diarios, revistas, libros, publicidades y campañas ambientales. No solo reconocemos estos elementos: los interpretamos como indicadores de la contaminación del agua y del aire, de la deforestación, del cambio climático global, de la extinción de especies, etcétera. Sin duda, la construcción de estas significaciones se ha ido dando a través de un entramado de discursos visuales en el cual el humor gráfico también participa.

Las intervenciones de la sociedad se presentan en las imágenes humorísticas retomando el dualismo naturaleza-sociedad. La naturaleza se muestra como un elemento estático que siempre es degradado, como una fuerza "naturalmente" destructiva, a partir de la intervención social. Aquí también encontramos conexiones con otros géneros de imágenes que cir- 
culan para comunicar ideas ambientales: la belleza se construye en torno a la representación pictórica o captura fotográfica de paisajes en los cuales se destaca su carácter prístino y estético en contraposición con la monotonía antiestética de los trazos que se configura en torno a paisajes industriales, urbanos, en resumen, socialmente transformados. La única intervención social que pareciera no resultar catastrófica es la observación de la naturaleza de carácter contemplativo.

Los escenarios de destrucción constituyen un lugar visitado con recurrencia en el humor gráfico. Es posible identificar conexiones con la frecuente recreación de escenarios apocalípticos, particularmente a través de la fotografía y del cine, para presentar ciertas preocupaciones ambientales (INGRAM, 2000). Sin embargo, algunos elementos propios del humor gráfico se conviertan en verdaderas ironías. El primer elemento que debemos señalar es que el humor gráfico establece claramente que tanto los autores como las audiencias se mueven en el campo ficcional. Por ello, lo que se pone de manifiesto entra en el terreno de la posibilidad y no de la necesariedad. Es decir, el carácter ficcional de la imagen hace que aún los escenarios más pesimistas incluyan la posibilidad de revertir el final anunciado desde la imagen y dejen abierta la posibilidad de que los lectores puedan imaginar otros finales. Un segundo elemento a tener en cuenta es que desde el humor gráfico la fuerza destructiva se coloca como algo antinatural. En las viñetas y tiras analizadas es la sociedad, basada en la idea de progreso ilimitado, el agente que produce el escenario del horror. No encontramos viñetas o tiras humorísticas que, como un grupo importante de fotografías de la revista, otorguen a la naturaleza esta fuerza destructiva. Por el contrario, desde el humor gráfico la naturaleza se representa como una fuerza creadora. No resulta un dato menor que desde este género de imágenes en la revista se presenta que nuestro desconocimiento de la naturaleza no sería la causa exclusiva de la posible destrucción de la Tierra.

\section{A MODO DE CIERRE: LA POTENCIA DEL HUMOR GRÁFICO}

Potencia de hacer ver aquello ante lo que quisiéra-
mos más bien cerrar los ojos... el arte nos invita a
abrir el ojo (Gerárd Wacjman, 1998:206/207)

Recorrer las imágenes "ambientales" que circulan a través de distintos registros visuales nos invita a indagar sobre los poderes de ellas. En otras palabras, podríamos preguntarnos $i$ En dónde reside la potencia o la fuerza del humor gráfico? ¿Qué encuentran en estas imágenes diferentes audiencias? ¿Qué incidencia tienen en nuestros modos de mirar una serie de temas ambientales como problemas? Para pensar algunos de estos interrogantes compartiré una experiencia de trabajo con imágenes con un grupo de adolescentes. En el marco de la Semana de la Ciencia y la Tecnología del año 2011 -un evento promovido para la difusión de investigaciones científicas a la comunidad-, propuse desarrollar un taller de imágenes ambientales. La audiencia estaba conformada por alumnos del último año de escuelas secundarias (entre 16 y 18 años de edad). La propuesta del taller comprendía cuatro momentos:

i- el encuentro con una selección de imágenes de diferentes géneros sobre temas ambientales (más de cuarenta imágenes impresas en hoja cartulina de tamaño A4),

ii- la elección individual de una imagen bajo la consigna de que ésta fuera "poderosa" para hacer una campaña publicitaria sobre el ambiente,

iii- la presentación de la imagen elegida y de los motivos de su elección en un grupo pequeño,

iv- la elección de la imagen más "poderosa" para el grupo y finalmente,

v- la elaboración de una frase para acompañar esa imagen.

La Figura 6, fue una de las imágenes elegidas como más "poderosas" en uno de los grupos de participantes. La frase que elaboraron para acompañarla sigue la línea de la ironía propuesta desde la viñeta: los tres deseos que el empresario podría decir antes de contaminar el lago; "prosperidad, impunidad, buena vida... ah... y beber con moderación".

Soc. \& Nat., Uberlândia, ano 24 n. 2, 227-242, mai/ago. 2012 
Figura 6: Las imágenes provocan y activan...

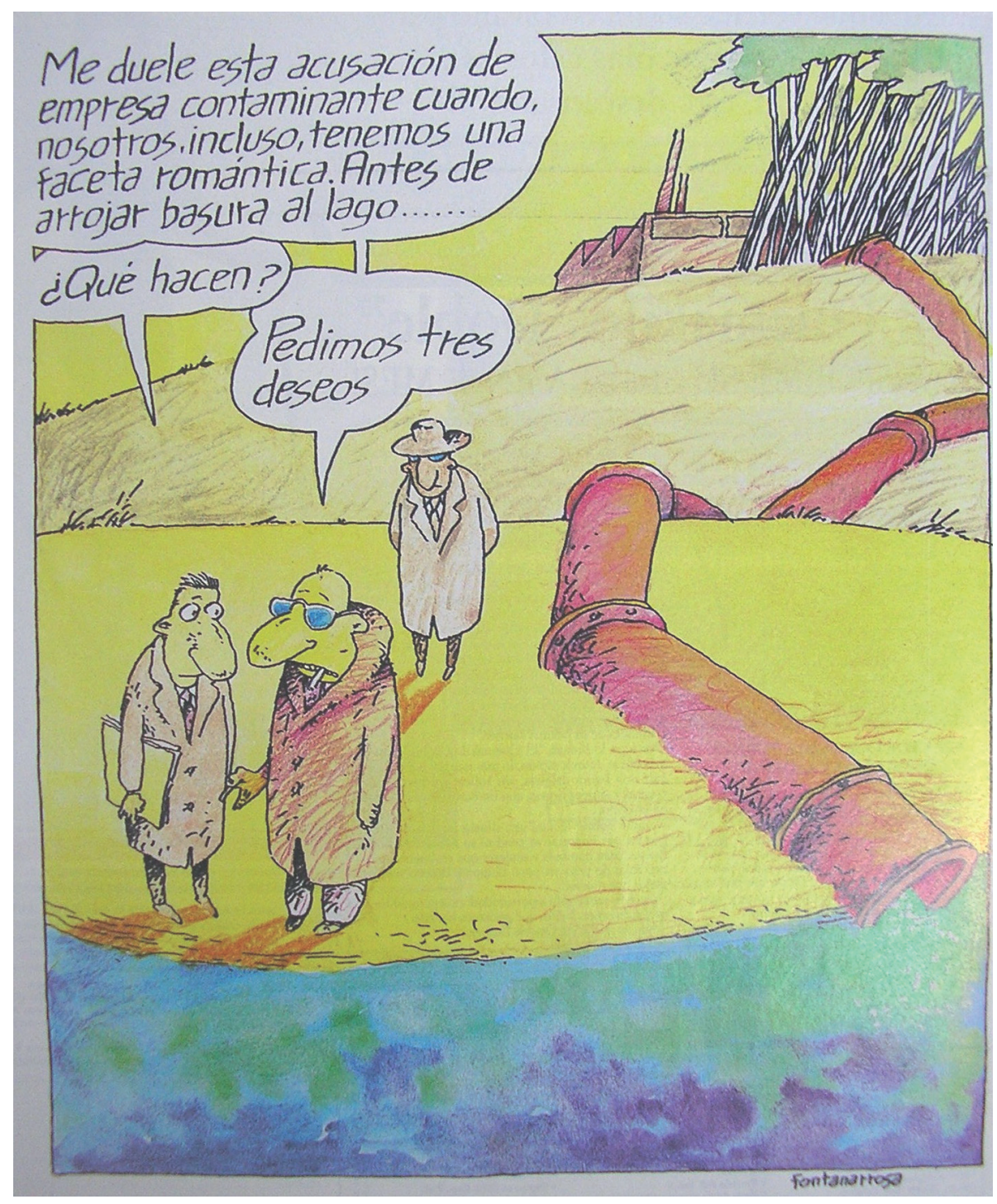

Fuente: Revista Viva, 13 de Noviembre 1994.

Autor: Fontanarrosa. Gentileza Hemeroteca de la Biblioteca Nacional.

¿Qué nos invita a pensar esta experiencia? En primer lugar, este género de imágenes tiene la potencialidad de captar los ojos de aquellos que no conocen o no están interesados en la cuestión ambiental. La risa se convierte en un llamado a los ojos que todavía no han sido seducidos por la preocupación ambiental. El poder de este género de imágenes comienza a desplegarse en la amplitud de su circulación y su llegada a ojos no especializados. Sorprende, entonces, la escasa utilización del humor gráfico en las campañas ambientales realizadas hasta la actualidad en Argentina y en el abordaje de contenidos ambientales en los manuales escolares. Consideramos que incorporar este género de imágenes podría suscitar el interés de audiencias no especializadas en el tema.

En segundo lugar, las imágenes humorísticas analizadas proponen mirar los problemas ambientales desde una perspectiva política y económica al poner 
en escena lógicas y relaciones que no son biológicas: actores sociales, lógica de acumulación, globalización de las economías y de la propia naturaleza, etcétera. Las imágenes humorísticas constituirían, de este modo, una valiosa incorporación para la educación ambiental al introducir perspectivas que, como señalan investigaciones previas, han sido excluidas de sus contenidos (PELEGRINI y VLACH, 2011).

En tercer lugar, la experiencia relatada nos sugiere que el poder de las imágenes, y en particular del humor gráfico, reside en lo que disparan, generan y activan en nosotros. Esta imagen invitó a estos jóvenes a ir más allá de lo que veían sus ojos: imaginar lo que diría ese empresario y así, reforzaron aún más la ironía propuesta por el humorista. Si retomamos aquí una idea de Didí-Huberman (2006) podríamos decir que la imagen disparó a mirar lo que no se ve en la viñeta: los motivos no explicitados de la actitud empresarial y el contexto socio-político que avala esta decisión empresaria. La viñeta, como diría el humorista argentino Rudy, estimuló el placer de pensar y de re-crear la situación.

En cuarto lugar, pareciera que el humor gráfico nos permite tomar distancia (una distancia que está dada por el carácter ficcional) y a la vez puede provocar una mirada comprometida: lo que se exhibe puede llegar a afectarnos a nosotros en primera persona. La definición de McCloud sobre el humor gráfico reconoce este poder: "yuxtaposición de imágenes pictóricas que presentadas en una secuencia deliberada intentan transmitir información y producir una respuesta estética en el espectador (McCloud, citado en MOORE, 2009). Las imágenes humorísticas analizadas operan como proposiciones que provocan una respuesta de quien las mira.

Finalmente, este taller de imágenes nos invita a pensar en la importancia de la educación de una mirada ambiental en contextos escolares. El proceso de elaboración que hicieron estos jóvenes para elegir una imagen y escribir una nueva leyenda no fue un resultado automático del encuentro con ella. Por el contrario, las experiencias y conocimientos previos - que conforman nuestra memoria ambiental- y la posibilidad de mirar y discutir las imágenes con otros, fueron esenciales en la producción de una nueva imagen. Se presenta así un doble desafío, es- timulante y comprometedor para quienes trabajamos en la formación de las nuevas generaciones. El primer desafío: un período histórico caracterizado por una mayor cantidad y disponibilidad de imágenes combinada con una creciente homogeneidad visual (HOLLMAN, 2010) nos obliga a pensar espacios y estrategias para fomentar prácticas de encuentro con las imágenes que las conecten con los imaginarios geográficos de nuestros alumnos, los cuestionen y enriquezcan. El segundo desafío: examinar y conocer las potencialidades y limitaciones de cada género de imágenes en relación a cada idea/ contenido que queremos comunicar y enseñar nos convoca a pensar la escuela y las disciplinas escolares como espacios para dar a ver y poner en diálogo imágenes variadas y diversas. Las imágenes humorísticas que hemos analizados tienen atributos particularmente potentes para introducir una perspectiva política, económica y cultural en la educación ambiental. Sin embargo, estas imágenes (como todas) no dan a ver todo. Entonces, en la agenda de la educación ambiental deberíamos examinar los posibles diálogos entre géneros de imágenes, ya no con el ideal de dar a ver todo sino con la finalidad de ofrecer perspectivas variadas, múltiples y hasta contradictorias que resulten disonantes a la homogeneidad visual existente.

\section{REFERENCIAS}

BAKER, S. They're there, and That's how We're seeing it. En: DOBRIN, S; S. MOREY (Eds.). Ecosee. Image, Rhetoric, Nature. Albany: State University of New York Press. 2009.

BRERETON, P. Hollywood Utopia. Ecology in Contemporary American Cinema. Portland: Intellect Books. 2005.

BURKART, M. 1960-2010. El humor gráfico entre dictaduras y democracia. En: Bicentenario. 200 años de humor gráfico. Buenos Aires: Museo de Artes Plásticas Eduardo Sívori. P. 16-17. Accesible en: $<$ http://www.museodeldibujo.com/images/sistema/ libros/pdf/catbicentenario.pdf $>$ (Último acceso 10 de Julio 2012).

Soc. \& Nat., Uberlândia, ano 24 n. 2, 227-242, mai/ago. 2012 
COSGROVE, D. Contested global visions: OneWorld, Whole-Earth, and the Apollo Space Photographs. En: Annals of the Association of American Geographers, 84 (2) P. 270-294. 1994.

CRONON, W. Uncommon Ground. Rethinking the Human Place in Nature. New York: WW. Norton \& Company Ltd. 1996.

DIDI-HUBERMAN G. Lo que vemos, lo que nos mira. Buenos Aires: Manantial, 2006.

DELUCA, M. Image Politics. The new rethoric of Enviromental Activism. New York: Routlegde. 1999.

PELEGRINI, D. F.; VLACH, V. F. As múltiplas dimensões da educação ambiental: por uma ampliação da abordagem. Sociedade \& Natureza, Uberlândia, Ano 23, N2, p. 187-196. 2011.

GORMAN, Q. Evading capture. The productive resitance of photography in Environmental Representation. En: DOBRIN, S; S. MOREY (Eds.) Ecosee. Image, Rhetoric, Nature. Albany: State University of New York Press. 2009.

HOLLMAN, V. Imágenes e imaginarios geográficos del mundo en la geografía escolar en Argentina. Anales de Geografía de la Universidad Complutense. Vol 30, n.1, p. 55-78. 2010. Accesible en:

$<$ http://revistas.ucm.es/ghi/02119803/articulos/AGUC1010120055A.PDF>, acesso em 2010.

INGRAM, D. Green Screen. Environmentalism and Hollywood Cinema. Exeter: University of Exeter Press. 2000.

KLEEMAN, G. Not just for fun: using cartoons to investigate geographical issues. New Zealand Geographer, 62, p. 144-151. 2006.

MIRZOEFF, N. Una introducción a la cultura visual. Barcelona: Paidos. 2003.

MOORE, A B. Maps as Comics, Comics as Maps. En: Proceedings, 24th International Cartography
Conference (ICC 2009), Santiago, Chile, Nov. 15-21, 2009. (CDROM, refereed paper). 2009.

MURRAY, R. \& HEUMANN, J. Ecology and popular film. Cinema on the edge, Alabany, State University of New York Press. 2009.

POOLE, R. Earthrise. How man first saw the Earth, New Haven: Yale University Press. 2009.

ROGOFF, I. Terra infirma. Geography's visual culture. London: Routledge. 2000.

SCHAWARTZ, J. The Geography Lesson: photographs and the construction of imaginative geographies. Journal of Historical Geography, 22, 1, p. 16-45. 1996.

SONTAG, S. Ante el dolor de los demás. Buenos Aires: Alfaguara. 2003.

WELLING, B. Ecoporn. On the limits of visualizing the Nonhuman. En: DOBRIN, S; S. MOREY (Eds.) Ecosee. Image, Rhetoric, Nature. Albany: State University of New York Press. 2009.

WAJCMAN, G. El objeto del siglo. Buenos Aires: Amorrortu Editores. 2001.

WILLOQUET-MARICONDI, P. Framing the world. Explorations in ecocriticism and film. Charlottesville: University of Virginia Press. 2010.

WOLFE, C. From Dead Meat to Glow-in-the-Dark Bunnies. Seeing the animal question in Contemporary Art, Em: DOBRIN, S; S. MOREY (eds.) Ecosee. Image, Rhetoric, Nature. Albany: State University of New York Press. 2009. 